\title{
Technological and Probiotic Traits of the Lactobacilli Isolated From Vaginal Tract of the Healthy Women for Probiotic Use
}

\author{
Hamida Bouridane 1,2, Mohamed Sifour ${ }^{4}$, Tayeb Idoui ${ }^{1 *}$, Lejeune Annick ${ }^{3}$, Philip Thonard 3 \\ ${ }^{1}$ Laboratoryof Biotechnology, Environment and Health, University Mohammed Seddik Benyahia, Jijel, Algeria \\ ${ }^{2}$ Department of Applied Microbiology and Food Sciences, Faculty of Sciences, University Mohammed Seddik Benyahia, \\ Jijel, Algeria \\ ${ }^{3}$ Bio-Industries Unit CWBI, Gembloux Agro. Bio-Tech, University of Liege, Passage Deportees, Gembloux, Belgium \\ ${ }^{4}$ Laboratory of Molecular Toxicology, Faculty of Sciences, University Mohammed Seddik Benyahia, Jijel, Algeria \\ ${ }^{*}$ Corresponding author: Idoui Tayeb, Department of Biotechnology, Environment and Health, University Mohammed Seddik Benyahia, Jijel, Algeria. \\ Tel/Fax: +213-34474896/97, E-mail: idoui@univ-jijel.dz
}

Received: December 31, 2015; Revised: March 12, 2016; Accepted: May 31, 2016

Background: For biotechnological application, selected lactic acid bacteria strains belonging to the genera Lactobacillus $(L b)$ are proposed as an alternative to the antibiotics for the prevention and treatment of urogenital tract infections.

Objectives: Isolating and selecting vaginal lactobacilli strains for probiotic use based on their technological and probiotic aptitudes.

Materials and Methods: The vaginal isolates were examined for their essential characteristics as the potential probiotic such as low pH tolerance, bile-salt and simulated human intestinal fluid (SIF) resistance, adhesion to the vaginal epithelial cells (VECs), aggregation and coaggregation, surface hydrophobicity, antimicrobial activity, acid production, antibiotic resistance, and resistance to spermicides. The best strain was identified by PCR.

Results: From 70 lactobacilli isolates and according to the 16 rDNA sequences, isolates B6 and B10 showed the closest homology (99\%) to the $L b$. gasseri and Lb. plantarum respectively. They produced hydrogen peroxide $\left(\mathrm{H}_{2} \mathrm{O}_{2}\right)$, tolerant to acid, bile, simulated human intestinal fluid, present a strong adhesion, highest percentages of aggregation, and antibacterial activity. These strains are resistant to the spermicide and actively acidify the growth medium.

Conclusions: Strains $L b$. plantarum B10 and $L$ b. gasseri $\mathrm{B} 6$ have a strong potential probiotic confirming their value as a tool for prevention against urinary and vaginal infections.

Keywords: Adherence; Aggregation; In vitro; Lactobacilli; PCR; Vaginal tract

\section{Background}

Urogenital tract infections (UGTI) and sexually transmitted infections are the two major medical problems, affecting millions of women every year (1-3). Although, antibiotic and drug therapy can be effective for the eradication of the urinary tract infection, however several problems have emerged, such as multiresistant bacteria (4-6). For the prevention and treatment of UGTI, probiotic lactobacilli were proposed as an alternative to the antibiotics $(7,8)$. Moreover, vaginal lactobacilli have a number of properties which render them highly suitable for probiotic $(5,9)$. A healthy vaginal women microbiota is dominated by lactobacilli. They play a significant role in the maintenance of ecological balance $(10,11)$. The protective role of lac- tobacilli is based on several mechanisms; specific adherence to the vaginal epithelium and inhibition of the pathogens adhesion to the vaginal epithelial surface, coaggregatin with some uropathogenic bacteria, competition for nutrients, production of the active metabolites including organic acid, mainly lactic acid that contributes in the maintenance of the low vaginal $\mathrm{pH}$ (4-4.5), hydrogen peroxide $\left(\mathrm{H}_{2} \mathrm{O}_{2}\right)$ is usually generated by lactobacilli present in a healthy vagina, production of bacteriocins $(5,10-12)$, but there are significant differences between strains (14). However, there are only few reports concerning probiotics residence in the female reproductive tract, although the presence of lactobacilli in vagina was observed by Doderlein in 1841 (6). 
The aim of this study was to get a better knowledge on the potential probiotic properties of the vaginal lactobacilli of the healthy Jijelian women (Algeria) in order to gain new indications on how to improve their exploitation in new the technological applications in probiotic production.

\section{Objectives}

The main goal of the present work was to isolate lactobacilli strains from vaginal samples and to investigate their probiotic properties.

\section{Materials and Methods}

\subsection{Vaginal Samples}

Vaginal specimens were obtained from 60 women (19-46 years) with healthy vaginal ecosystem of Jijel region. From vaginal fluid, samples were collected with sterile cotton swabs inserted into the vagina, rotated a few turns along the vaginal sidewall, and allowed to absorb for few seconds (15). The swabs were immersed in the sterile normal saline, and used for anaerobic (BD Gaspak ${ }^{\mathrm{TM}}$ Anaerobic system, USA) culture preparation by streaking on de Man Rogasa Sharpe (MRS) Agar (CONDA, Pronadisa, Spain) plates (16). The same swab was used to prepare a smear, underwent Gram staining, and was evaluated by using Nugent criteria. The flora was interpreted as normal (score 0-3), as intermediate (score 4-6), and interpreted as consistent with BV (score 7-10) (17).

\subsection{Isolation and Identification of Microorganisms}

The swabs were vortexed for $1 \mathrm{~min}$ at maximum speed, the resultants suspensions were diluted 7 times with potassium phosphate buffer ( $\mathrm{pH} 7.4$ ), and $50 \mu \mathrm{L}$ of each dilution was seeded on MRS agar plate $(\mathrm{pH}$ 5.5). The plates were incubated for $48 \mathrm{~h}$ at $37^{\circ} \mathrm{C}$ under anaerobic condition $(16,18)$. To identify strains, each colony was subjected to colony morphology, Gram coloration, catalase activity test, motility, growth at various temperatures, and homofermentative/heterofermentative test. They were further characterized by the carbohydrate fermentation, then stored at $-20^{\circ} \mathrm{C}$ in MRS broth supplemented with glycerol (30\% v/v) (13, 19).

\subsection{Determination of Hydrogen Peroxide Produced by Lactobacilli}

Isolates were cultured into MRS agar medium supplemented with $250 \mu \mathrm{g} . \mathrm{mL}^{-1}$ 3,3',5,5'-tetramethylbenzidine (Sigma-Aldrich, USA) and $0.01 \mathrm{mg} . \mathrm{mL}^{-1}$ horse- radish peroxidase (Sigma-Aldrich, USA), incubated in an anaerobic condition at $37^{\circ} \mathrm{C}$ for $48 \mathrm{~h}$. The plates were exposed to aerobic environment for $30 \mathrm{~min}$. The color intensity was graded the potential of $\mathrm{H}_{2} \mathrm{O}_{2}$ production $(20,21)$.

\subsection{Determination of Acid and Bile Salt Tolerance}

Fourteen (14) isolates $\left(\mathrm{H}_{2} \mathrm{O}_{2}^{+}\right)$were cultured for 16-18 $\mathrm{h}$ and the cells were collected by centrifugation $(30000 \times \mathrm{g}, 15 \mathrm{~min})$. The pellet were washed twice and finally suspended in phosphate buffer saline (PBS). Approximately $10^{8}$ CFU.mL-1 of each isolate was inoculated into the acidified PBS pH 2.0 and incubated for up $2 \mathrm{~h}$. The viable cells were counted at $0 \mathrm{~h}$ and after $2 \mathrm{~h}$ (22). The bile tolerance of each isolate was determined by comparing the count after $8 \mathrm{~h}$ of exposure to $0.3 \%$ bile salt Oxgall (Sigma-Aldrich, USA), (w/.v) with initial count at $0 \mathrm{~h} \mathrm{(22).}$

\subsection{Survival in Simulated Human Intestinal Fluid}

Simulated intestinal fluid (SIF) was prepared with 9 g.L.-1 NaCl, 10 g.L - $^{-1}$ of pancreatin, 10 g.L.-1 trypsin and 3 g. $\mathrm{L}^{-1}$ of bile salts $(\mathrm{pH}$ 6.5). The cultures were incubated in this solution for $180 \mathrm{~min}$ at $37^{\circ} \mathrm{C}$. The number of viable cells was counted at $0 \mathrm{~h}, 90 \mathrm{~min}$ and after $180 \min (23)$.

\subsection{Adhesion to Vaginal Epithelial Cells (VECs)}

VECs were collected from healthy premenopausal volunteers' women by sterile cotton swabs, immersed in $0.04 \mathrm{M}$ citric acid $-\mathrm{Na}_{2} \mathrm{HPO}_{4}$ buffer $\mathrm{pH} 4.5$ and stored at $4^{\circ} \mathrm{C}$ for less than $3 \mathrm{~h}$ until use. The VECs were washed using the same buffer, centrifuged at $800 \times \mathrm{g}$ for $4 \mathrm{~min}$ and resuspended to a concentration of $1 \times 10^{6}$ VEC.mL-1 (24). An overnight culture of the lactobacilli was suspended to reach $10^{8}$ CFU.mL ${ }^{-1}$ in normal saline. Equal volumes of the bacterial suspension and the vaginal cells were mixed and incubated for $1 \mathrm{~h}$ at $37^{\circ} \mathrm{C}$ and the cells with adherent bacteria were collected and washed three times in citric-acid- $\mathrm{Na}_{2} \mathrm{H}_{2} \mathrm{PO}_{4}$ buffer $(800 \times \mathrm{g}$, $7 \mathrm{~min})$. Bacterial adhesion to VECs was assessed by microscopy $(\times 100)$ after staining with $1 \%$ of crystal violet. The number of bacteria attached to 50 consecutive VECs smears was counted and VECs Controls smears were made to confirm that the presence of native bacteria was negligible (15).

\subsection{Growth Inhibition of Vaginal and Urogenital Pathogens \\ Indicator strains used were E. coli ATCC25922, Staphylococcus aureus ATCC25923, Klebsiella pneu-}


monia ATCC700603 (UHC, Constantine, Algeria), vaginal strains (E. coli, Staphylococcus aureus, Candida albicans) and urogenital strains (E. coli, Klebsiella. sp).

Inhibitory activity was determined by well diffusion test with minor modifications (17). The surface of Muller-Hinton agar plate was spread with a standardized suspension of each pathogen microorganisms $\left(10^{7} \mathrm{CFU} \cdot \mathrm{mL}^{-1}\right)$. Culture supernatants of the lactobacilli isolates were filtered through $0.45 \mu \mathrm{m}$ cellulose filter (Sartorius, Germany). $25 \mu \mathrm{L}$ of the cultures and supernatants of lactobacilli were placed into wells in the pathogens inoculated plates and were incubated for $24 \mathrm{~h}$ at $37^{\circ} \mathrm{C}$. The diameter of inhibition zones was measured. Control assays of MRS medium with $\mathrm{pH}$ 6.5 and $\mathrm{pH} 4.0$ were also performed (5).

\subsection{Autoaggregation and Coaggregation Assay}

Bacterial cells of overnight culture were harvested by centrifugation at $5000 \times \mathrm{g}$ for $15 \mathrm{~min}$, washed twice in PBS pH 6.0 to give viable counts of $10^{8}$ CFU.mL ${ }^{-1}$. Four $\mathrm{ml}$ of cell suspension were mixed by vortexing for $10 \mathrm{~s}$ and autoaggregation was determined during $5 \mathrm{~h}$ of incubation at room temperature. $0.1 \mathrm{~mL}$ of the upper suspension was transferred to another tube containing $3.9 \mathrm{~mL}$ PBS and the absorbance was measured at $600 \mathrm{~nm}$ (25). The percentage of autoaggregation was calculated by the following expression:

\section{Autoaggregation $(\%)=\left[\mathrm{OD}_{\mathrm{i}}-\mathrm{OD}_{\mathrm{f}} / \mathrm{OD}_{\mathrm{i}}\right] \times 100$}

Where $\mathrm{OD}_{\mathrm{i}}$ is the $\mathrm{OD}$ at initial time $(\mathrm{t}=0 \mathrm{~h})$ of autoaggregation assay, and $\mathrm{OD}_{\mathrm{f}}$ is the $\mathrm{OD}$ at $\mathrm{t}=1 \mathrm{~h}, 2 \mathrm{~h}$, $3 \mathrm{~h}, 4 \mathrm{~h}$ and $5 \mathrm{~h}$.

For the co-aggregation experiment, equal volumes $(2 \mathrm{~mL})$ of the lactobacilli and indicator strain cultures were mixed together by vortexing for $10 \mathrm{~s} .4 \mathrm{~mL}$ of each bacterial suspension were used as a control. The absorbance was measured at $600 \mathrm{~nm}$ after mixing and $5 \mathrm{~h}$ of incubation at room temperature (25). The percentage of coaggregation was calculated using the following equation:

$$
\% \text { Coaggregation }=\frac{\left[\left(\mathrm{A}_{\mathrm{x}}+\mathrm{A}_{\mathrm{y}}\right) / 2\right]-\mathrm{A}(\mathrm{x}+\mathrm{y})}{\left[\mathrm{A}_{\mathrm{x}}+\mathrm{A}_{\mathrm{y}}\right] / 2} \times 100
$$

$\mathrm{x}$ and $\mathrm{y}$ represent strains in the control tube and $(\mathrm{x}+\mathrm{y})$ the mixture.

\subsection{Hydrophobic Partition}

Bacterial pellets were obtained from overnight cul- tures, washed, and resuspended in urea magnesium phosphate buffer ( $\mathrm{pH}$ 6.0). The absorbance of the cell suspension was measured at $450 \mathrm{~nm}$ to obtain approximately 1.0. Three $\mathrm{mL}$ of the bacterial suspensions were put in contact with $0.6 \mathrm{~mL}$ of xylene and vortexed for $2 \mathrm{~min}$. The lower aqueous layer was carefully removed, transferred to the clean tubes, and absorbance was measured as described before (26). The percentage of hydrophobicity was obtained from the following calculation:

$\%$ hydrophobicity $=\left[\left(\mathrm{OD}_{\text {before }}-\mathrm{OD}_{\text {after }}\right)\right] / \mathrm{OD}_{\text {before }} \times 100$

\subsection{Acid Production}

Lactobacilli strains were inoculated (1\%) in MRS broth ( $\mathrm{pH}$ 6.5) and the amount of acids produced was indirectly determined by measuring the $\mathrm{pH}$ of culture supernatants with a $\mathrm{pH}$ meter (HANNA, HI 2211/ PH/ ORP Meter). The experiments were performed in duplicate and the mean $\mathrm{pH} \pm \mathrm{S}$.D was calculated (9).

\subsection{Antibiotic Resistance}

The antibiotics used were inhibitors of the cell wall synthesis such as Ampicillin (10 $\mu \mathrm{g})$, Cefotaxime (30 $\mu \mathrm{g})$, inhibitor of protein synthesis (Gentamicin $(10 \mu \mathrm{g})$, Erythromycin $(15 \mu \mathrm{g})$, Chloramphenicol $(30 \mu \mathrm{g})$, Tetracycline $(30 \mu \mathrm{g})$ and inhibitor of nucleic acid synthesis (Ofloxacin, $(5 \mu \mathrm{g})$, Trimethoprim-sulphamethoxazole $(25 \mu \mathrm{g})$, Ciprofloxacin $(5 \mu \mathrm{g})$, Nitrofurantoin $(200 \mu \mathrm{g})$. Antibiotic discs were obtained from (Bioanalyse ${ }^{\circledR}$ ). The disk diffusion method was used. After incubation the diameters of the inhibition zone were measured $(5,27)$.

\subsection{Resistance to Spermicides}

Suspensions of 14 isolates were adjusted to $10^{8}$ CFU.mL ${ }^{-1}$ and then were inoculated by swabbing onto MRS agar. $10 \mu \mathrm{L}$ of each concentration $(0.1 \%, 0.25 \%$, $1 \%$, and $2.5 \%$ ) of nonoxynol-9 $(\mathrm{N}-9)$ cream was deposited on each disk. After incubation, the strain was considered sensitive if the diameter of the inhibition zone is more than $9 \mathrm{~mm}(20)$.

\subsection{Genetic Identification of the Best Lactobacilli}

To identify the most efficient isolates, 16S Ribosomal DNA (16S-rDNA) sequencing was performed. Genomic DNA was extracted with the Wizard ${ }^{\circledR}$ genomic DNA purification kit (Promega, Madison, USA) according to the manufacturer instruction. To amplify 16S-rDNA, polymerase chain reaction (PCR) was used with the following primers 16SP0: 5'-GAAGAGTTTGATCCTGGCTCAG-3' and 16SP65'-CTACG- 
GCTACCTTGTTACGA-3'. Fragment of about 1500 bp in size was excised from a $1 \%$ (w.v) agarose gel staining and purified with Microcon YM-100 kit (Bedford, MA, USA). The BigDye Terminator sequence was performed using the Vector NTI (Version 8) software package (BD Biosciences, San Jose, USA). The sequences were compared with sequences deposited in the Gen Bank database of the National Center for Biotechnology Information using the BLAST program. The phylogenetic tree was generated by Tree Dyn program (v198.3) proposed by Methods and Algorithms for Bioinformatics LIRMM. (http://phylogeny.lirmm.fr/phylo_cgi/simple phylogeny.cgi).

\subsection{Statistical Analysis}

Results are expressed as the mean \pm standard (SD). Statistical differences were analyzed by one way analysis of variance (ANOVA) using SPSS software (version 13) and $p$ values $<0.05$ were considered to be statistically significant.

\section{Results}

\subsection{Selection of Vaginal Lactobacilli and $\mathrm{H}_{2} \mathrm{O}_{2}$} Production

Using Nugent Scoring System, twenty four women $(40 \%)$ were classified as having normal vaginal flora, $16(26.66 \%)$ were intermediate and $20(33.33 \%)$ were BV. 40 samples that have score $<7$ were retained. From these samples, 70 lactobacilli isolates were obtained.

In this study we used the capacity of producing

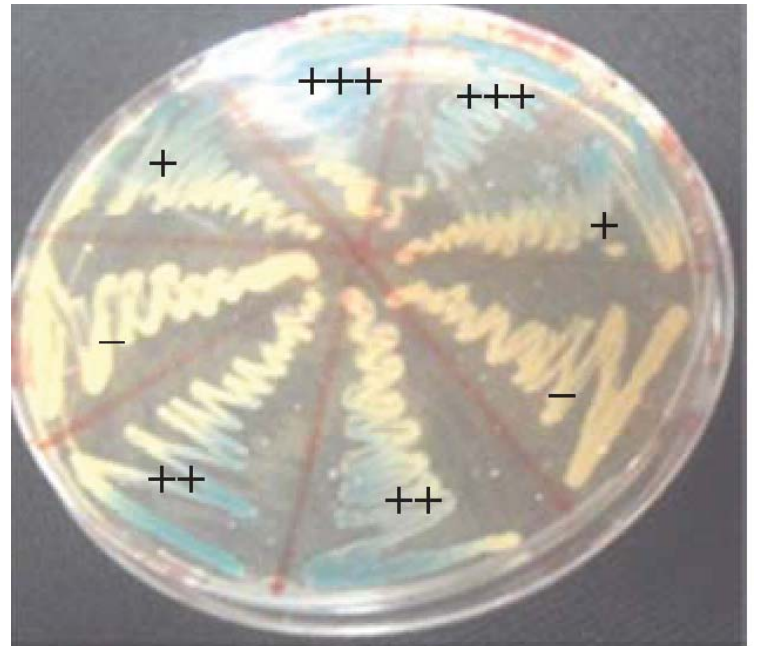

Figure 1. Identification of the hydrogen peroxide production by the isolated lactobacilli: $(+++)$ high production; $(++)$ medium production; and (+) low production. (-) indicates no production

$\mathrm{H}_{2} \mathrm{O}_{2}$ as the first criterion of selection. As shown in (Figure 1), potential production of $\mathrm{H}_{2} \mathrm{O}_{2}$ capacity was divided into 4 groups according to the intensity of the color. Among the 70 isolates, $57(81.42 \%)$ were found to be able to produce $\mathrm{H}_{2} \mathrm{O}_{2}$ and $26(37.14 \%)$ were hyperproducers. In this study, isolates producing $\mathrm{H}_{2} \mathrm{O}_{2}$ were selected to evaluate their potential traits.

\subsection{Survival Under Acidic, Bile and SIF Conditions \\ Most isolates show considerable tolerance to acid condition with different percentage, where strains B6,}

Table 1. Effect of acidic conditions ( $\mathrm{pH} 2.0)$ bile salts $(0.3 \%)$ and simulated human intestinal fluid on the survival of vaginal Lactobacillus isolates

\begin{tabular}{|c|c|c|c|c|c|c|c|}
\hline \multirow[t]{2}{*}{ Isolates } & \multicolumn{2}{|c|}{$\begin{array}{c}\text { survival rate }(\%) \\
\text { pH } 2.0\end{array}$} & \multicolumn{2}{|c|}{$\begin{array}{l}\text { survival rate }(\%) \\
\text { bile salts }(0.3 \%)\end{array}$} & \multicolumn{3}{|c|}{$\begin{array}{l}\text { survival rate }(\%) \\
\text { simulated human intestinal fluid }\end{array}$} \\
\hline & $\mathrm{Oh}$ & $2 \mathrm{~h}$ & $\mathrm{Oh}$ & $8 \mathrm{~h}$ & $\mathbf{O h}$ & $90 \mathrm{~min}$ & $180 \mathrm{~min}$ \\
\hline A1 & 100 & 67,71 & 100 & 52,91 & 100 & 60.43 & 45.54 \\
\hline $\mathrm{A} 2$ & 100 & 48,13 & 100 & 55,76 & 100 & 79.72 & 58.88 \\
\hline A3 & 100 & 54,84 & 100 & 71,84 & 100 & 73.90 & 37.41 \\
\hline A4 & 100 & 59,72 & 100 & 30,96 & 100 & 46.51 & 27.06 \\
\hline A5 & 100 & 50,65 & 100 & 56,14 & 100 & 51.96 & 31.68 \\
\hline B1 & 100 & 72,43 & 100 & 35,13 & 100 & 52.26 & 23.56 \\
\hline B3 & 100 & 40,22 & 100 & 53,36 & 100 & 86.34 & 63.95 \\
\hline B4 & 100 & 62,95 & 100 & 31,90 & 100 & 67.47 & 51.40 \\
\hline B6 & 100 & 82,23 & 100 & 77,38 & 100 & 74.44 & 67.41 \\
\hline B9 & 100 & 69,08 & 100 & 36,52 & 100 & 56.60 & 34.89 \\
\hline B10 & 100 & 79,98 & 100 & 59,54 & 100 & 71.93 & 60.59 \\
\hline $\mathrm{C} 3$ & 100 & 62,83 & 100 & 51,77 & 100 & 62.95 & 41.68 \\
\hline C5 & 100 & 55,70 & 100 & 39,97 & 100 & 55.43 & 26.48 \\
\hline W5 & 100 & 44,76 & 100 & 36.00 & 100 & 55.71 & 43.54 \\
\hline
\end{tabular}




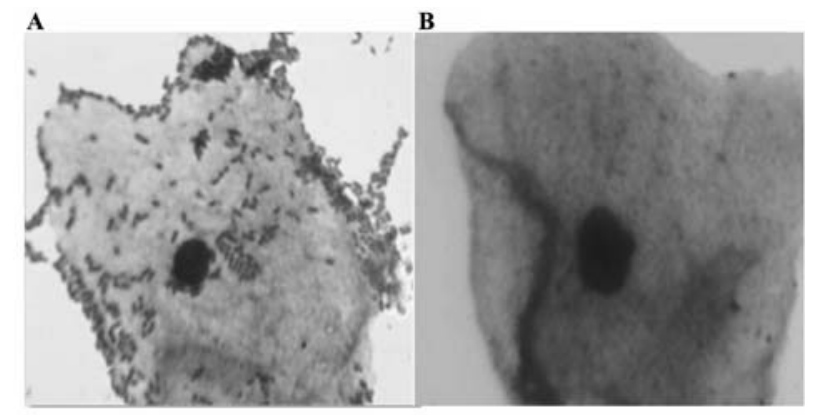

Figure 2. A: Adherence of isolate B6 to vaginal epithelial cells. B: Control

B10, and B9 had high tolerance with $82.23 \% ; 79.98 \%$, and $69.08 \%$ survival rates respectively (Table 1).

Concerning the resistance of the same isolates to $0.3 \%$ bile-salts for $2 \mathrm{~h}$, an important viability was noted. It was $71.84 \%$ for strain A3, $77.38 \%$ for B6, and $59.54 \%$ for B10 (Table 1). The results showed the high differences between strains after incubation for 180 min in SIF. Isolate B10 represent $71.93 \%$ survival rate after 90 min of incubation and reached to $60.59 \%$ after 180 min (Table 1). It' is appearing that strains B6 and B10 have the ability to resist to hostiles conditions.

\subsection{Adhesion to Vaginal Epithelial Cells, Aggregation,} Hydrophobicity, and Coaggregation

The highest levels of adhesion was observed for the strains B6 (Figure 2), and C3 with the means of 76, and 80 bacteria per VEC, respectively, while other strains such as A1, A3, B9, B10, C5, and W5 adhered less well to VEC with a mean adherence of 60 bacteria at most (Table 2).

The results showed that the isolates adhered to VEC with varying degrees, where isolates $\mathrm{C} 3, \mathrm{~B} 6$, and $\mathrm{B} 10$ were the most adhesives. Bacterial aggregation between microorganisms is one of the important defense mechanism against infection of UGT. Strongly autoaggregating strains A1, A3, B6, B3, B4, B9, B 10, and $\mathrm{C} 3$ showed a high autoaggregation percentage between 53 and $73 \%$ (Table 2).

The percentages of hydrophobicity toward xylene are shown in (Table 2). Hydrophobic cell surface was demonstrated by high adherence to xylene, an apolar solvent. Our results demonstrated that all tested strains had lower hydrophobicity, where the highest percentage is represented by strain B6 with $34.06 \%$.

In the present study, no correlation was observed between cell surface hydrophobicity, ability to adhere to the vaginal cell and auto aggregation because all strains have low hydrophobicity while some isolates have a very strong ability of adhesion.

The results of co aggregation showed that the highest $S$. aureus coaggregation percentage were obtained with strains B3 (54.02\%) and B6 (52.12\%) after $5 \mathrm{~h}$ of incubation, respectively. The co aggregation with $E$. coli is lower, where $38.05 \%$ is the highest percentage with strain B10 (Table 2).

Table 2. Ability of Lactobacillus isolates to adhere to vaginal epithelial cells, percentage of auto aggregation percentage of hydrophobicity and Coaggregation ability

\begin{tabular}{|c|c|c|c|c|c|c|c|c|c|}
\hline \multirow[t]{2}{*}{ Isolates } & \multirow{2}{*}{$\begin{array}{c}\text { Adherents to VECs } \\
\text { (bacteria/ VECs) } \\
\text { pH } 2.0\end{array}$} & \multicolumn{5}{|c|}{ Autoaggregation (\%) } & \multirow[t]{2}{*}{$\begin{array}{l}\text { Hydrophobicity } \\
(\%)\end{array}$} & \multicolumn{2}{|c|}{$\begin{array}{c}\text { Coaggregation after } 5 \mathrm{~h} \text { of } \\
\text { incubation (\%) }\end{array}$} \\
\hline & & $1 \mathrm{~h}$ & $2 \mathrm{~h}$ & $3 \mathrm{~h}$ & $4 \mathrm{~h}$ & $5 \mathrm{~h}$ & & $\begin{array}{l}\text { S. aureus } \\
\text { (Vaginal) }\end{array}$ & $\begin{array}{l}\text { E. coli } \\
\text { (Vaginal) }\end{array}$ \\
\hline $\mathrm{A} 1$ & 65 & 40.81 & 45.69 & 58.05 & 62.93 & 67.82 & 23.33 & 04.16 & 03.35 \\
\hline $\mathrm{A} 2$ & 45 & 25.00 & 46.88 & 48.44 & 50.00 & 51.03 & 13.87 & 15.33 & 26.02 \\
\hline A3 & 67 & 33.14 & 45.94 & 46.09 & 53.62 & 55.51 & 17.11 & 35.17 & 24.26 \\
\hline A4 & 33 & 5.45 & 9.09 & 16.36 & 35.5 & 45.09 & 10.70 & 22.01 & 12.06 \\
\hline A5 & 52 & 10.81 & 12.74 & 33.59 & 41.98 & 43.85 & 29.34 & 14.89 & 33.87 \\
\hline B1 & 53 & 17.59 & 24.07 & 31.48 & 32.41 & 47.22 & 8.29 & 08.25 & 07.35 \\
\hline B3 & 45 & 27.44 & 35.00 & 58.31 & 62.26 & 63.59 & 45.15 & 54.02 & 04.92 \\
\hline B4 & 50 & 15.00 & 27.00 & 33.00 & 52.50 & 55.00 & 00.00 & 14.66 & 30.65 \\
\hline B6 & 76 & 35.00 & 45.92 & 47.00 & 68.00 & 73.00 & 34.06 & 52.12 & 25.80 \\
\hline B9 & 68 & 12.99 & 49.15 & 50.05 & 54.24 & 58.76 & 16.32 & 27.66 & 37.92 \\
\hline B10 & 63 & 10.15 & 17.00 & 42.00 & 57.28 & 69.50 & 14.63 & 35.00 & 38.05 \\
\hline C3 & 80 & 16.32 & 27.63 & 43.16 & 49.47 & 63.74 & 00.00 & 38.88 & 31.70 \\
\hline C5 & 68 & 14.73 & 14.73 & 41.09 & 41.86 & 48.06 & 10.20 & 16.33 & 06.04 \\
\hline W5 & 67 & 27.15 & 32.65 & 44.66 & 50.00 & 50.22 & 32.60 & 33.82 & 31.17 \\
\hline
\end{tabular}


Table 3. Growth inhibition zones of vaginal, urinary and ATCC strains caused by some lactobacilli and supernatants Strains and supernatants. Mean zone of inhibition of the indicator strains ( $\mathrm{mm})$

\begin{tabular}{|c|c|c|c|c|c|c|c|c|}
\hline \multirow{2}{*}{$\begin{array}{l}\text { Strains and } \\
\text { supernatants }\end{array}$} & \multicolumn{3}{|c|}{ Vaginal strains } & \multicolumn{3}{|c|}{ ATCC strains } & \multicolumn{2}{|c|}{ Urinary strains } \\
\hline & E. coli & $\begin{array}{c}\text { Staphylococcus } \\
\text { sp. }\end{array}$ & Candida sp. & $\begin{array}{c}\text { E. coli } \\
\text { ATTC25922 }\end{array}$ & $\begin{array}{c}\text { S. aureus } \\
\text { ATTC25923 }\end{array}$ & $\begin{array}{l}\text { K. pneumonia } \\
\text { ATTC } 700603\end{array}$ & E. coli & $\begin{array}{c}\text { Klebsiella } \\
\text { sp. }\end{array}$ \\
\hline A1 & $10.5 \pm 0.5$ & $14.0 \pm 1.0$ & $00 \pm 00$ & $14.5 \pm 0.5$ & $14.5 \pm 0.5$ & $12.0 \pm 1.0$ & $14.5 \pm 1.5$ & $13.5 \pm 0.5$ \\
\hline S.A1 & $00 \pm 00$ & $00 \pm 00$ & $00 \pm 00$ & $12.5 \pm 0.5$ & $00 \pm 00$ & $00 \pm 00$ & $00 \pm 00$ & $12.0 \pm 1.0$ \\
\hline $\mathrm{A} 2$ & $10.0 \pm 1.0$ & $15.5 \pm 0.5$ & $00 \pm 00$ & $14.5 \pm 1.5$ & $13.5 \pm 0.5$ & $10.5 \pm 0.5$ & $13.0 \pm 1.5$ & $11.5 \pm 0.5$ \\
\hline S.A2 & $00 \pm 00$ & $00 \pm 00$ & $00 \pm 00$ & $14.0 \pm 1.0$ & $00 \pm 00$ & $08.0 \pm 1.0$ & $00 \pm 00$ & $12.0 \pm 0.0$ \\
\hline A3 & $11.5 \pm 0.5$ & $12.0 \pm 1.0$ & $00 \pm 00$ & $00 \pm 00$ & $15.0 \pm 2.0$ & $12.5 \pm 1.5$ & $13.5 \pm 2.5$ & $13.5 \pm 0.5$ \\
\hline S.A3 & $00 \pm 00$ & $00 \pm 00$ & $00 \pm 00$ & $15.5 \pm 0.5$ & $00 \pm 00$ & $10.5 \pm 0.5$ & $00 \pm 00$ & $12.0 \pm 0.0$ \\
\hline $\mathrm{A} 4$ & $00 \pm 00$ & $15.5 \pm 1.5$ & $00 \pm 00$ & $12.0 \pm 1.0$ & $14 \pm 0.0$ & $00 \pm 00$ & $11.5 \pm 0.5$ & $9.5 \pm 1.5$ \\
\hline S. A4 & $00 \pm 00$ & $00 \pm 00$ & $00 \pm 00$ & $00 \pm 00$ & $00 \pm 00$ & $00 \pm 00$ & $00 \pm 00$ & $14.5 \pm 0.5$ \\
\hline A5 & $12.0 \pm 1.0$ & $14.5 \pm 0.5$ & $00 \pm 00$ & $14.5 \pm 0.5$ & $13.5 \pm 0.5$ & $13.5 \pm 0.5$ & $12.5 \pm 0.5$ & $13.5 \pm 1.5$ \\
\hline S.A5 & $00 \pm 00$ & $00 \pm 00$ & $00 \pm 00$ & $14.5 \pm 0.5$ & $00 \pm 00$ & $00 \pm 00$ & $00 \pm 00$ & $12.5 \pm 0.5$ \\
\hline B1 & $12.5 \pm 0.5$ & $11.0 \pm 1.0$ & $9.0 \pm 1.0$ & $12.0 \pm 2.0$ & $00 \pm 00$ & $15.5 \pm 0.5$ & $8.5 \pm 0.5$ & $12.0 \pm 1.0$ \\
\hline S.B1 & $00 \pm 00$ & $00 \pm 00$ & $00 \pm 00$ & $11.0 \pm 1.0$ & $00 \pm 00$ & $12.0 \pm 1.0$ & $00 \pm 00$ & $00 \pm 00$ \\
\hline B3 & $00 \pm 00$ & $00 \pm 00$ & $00 \pm 00$ & $11.5 \pm 0.5$ & $00 \pm 00$ & $00 \pm 00$ & $00 \pm 00$ & $16.5 \pm 0.5$ \\
\hline S.B3 & $00 \pm 00$ & $00 \pm 00$ & $00 \pm 00$ & $00 \pm 00$ & $00 \pm 00$ & $00 \pm 00$ & $00 \pm 00$ & $9.0 \pm 1.0$ \\
\hline B4 & $08.5 \pm 0.5$ & $12.5 \pm 0.5$ & $11.5 \pm 0.5$ & $11.0 \pm 0.0$ & $12.0 \pm 1.0$ & $00 \pm 00$ & $13.5 \pm 0.5$ & $9.0 \pm 1.5$ \\
\hline S.B4 & $00 \pm 00$ & $00 \pm 00$ & $00 \pm 00$ & $12.0 \pm 1.0$ & $00 \pm 00$ & $00 \pm 00$ & $13.0 \pm 1.0$ & $12.0 \pm 1.0$ \\
\hline B6 & $15.5 \pm 1.5$ & $12.0 \pm 2.0$ & $14.0 \pm 1.0$ & $00 \pm 00$ & $10.5 \pm 1.5$ & $13.5 \pm 1.5$ & $14.5 \pm 0.5$ & $9.5 \pm 0.5$ \\
\hline S.B6 & $00 \pm 00$ & $14.0 \pm 1.0$ & $10.0 \pm 1.0$ & $00 \pm 00$ & $11.0 \pm 1.0$ & $00 \pm 00$ & $00 \pm 00$ & $13.5 \pm 0.5$ \\
\hline B9 & $00 \pm 00$ & $8.0 \pm 3.0$ & $00 \pm 00$ & $15.0 \pm 2.0$ & $00 \pm 00$ & $00 \pm 00$ & $00 \pm 00$ & $13.5 \pm 0.5$ \\
\hline S.B9 & $00 \pm 00$ & $00 \pm 00$ & $00 \pm 00$ & $00 \pm 00$ & $00 \pm 00$ & $00 \pm 00$ & $00 \pm 00$ & $12.5 \pm 2.5$ \\
\hline B10 & $15.0 \pm 1.0$ & $16.5 \pm 0.5$ & $10.5 \pm 1.0$ & $10.5 \pm 1.5$ & $14.5 \pm 0.5$ & $11 \pm 1$ & $14.5 \pm 0.5$ & $12.5 \pm 0.5$ \\
\hline S. B10 & $00 \pm 00$ & $12.0 \pm 0.1$ & $9.0 \pm 0.1$ & $00 \pm 00$ & $00 \pm 00$ & $00 \pm 00$ & $13.0 \pm 2.0$ & $13.0 \pm 0.0$ \\
\hline C3 & $12.0 \pm 1.0$ & $12.0 \pm 1.0$ & $14.0 \pm 1.0$ & $14.0 \pm 1.0$ & $13.0 \pm 1.0$ & $00 \pm 00$ & $12.5 \pm 0.5$ & $00 \pm 00$ \\
\hline S.C3 & $00 \pm 00$ & $00 \pm 00$ & $00 \pm 00$ & $12.5 \pm 0.5$ & $00 \pm 00$ & $00 \pm 00$ & $12.5 \pm 0.5$ & $00 \pm 00$ \\
\hline C5 & $14.5 \pm 1.5$ & $16.0 \pm 1.0$ & $11.5 \pm 1.5$ & $15.5 \pm 0.5$ & $13.0 \pm 1.0$ & $00 \pm 00$ & $13.0 \pm 1.0$ & $11.0 \pm 1.0$ \\
\hline S.C5 & $00 \pm 00$ & $00 \pm 00$ & $00 \pm 00$ & $15.5 \pm 0.5$ & $00 \pm 00$ & $00 \pm 00$ & $00 \pm 00$ & $00 \pm 00$ \\
\hline W5 & $13.0 \pm 1.0$ & $20.5 \pm 1.5$ & $00 \pm 00$ & $16.5 \pm 0.5$ & $23.5 \pm 0.5$ & $13.5 \pm 0.5$ & $15.5 \pm 0.5$ & $12.5 \pm 0.5$ \\
\hline S.W5 & $10.0 \pm 1.0$ & $00 \pm 00$ & $00 \pm 00$ & $13.5 \pm 0.5$ & $00 \pm 00$ & $11.0 \pm 0.0$ & $11.5 \pm 0.5$ & $13.5 \pm 0.5$ \\
\hline
\end{tabular}

S: Supernatant

\subsection{Growth Inhibition of Vaginal and Urogenital Pathogens}

The results showed that our isolates have exhibited inhibitory activity against pathogenic strains with a significant difference $(\mathrm{p}<0.05)$ (Table 3$)$. The smallest diameter of inhibition zone was $9 \mathrm{~mm}$ and the widest was $20.5 \mathrm{~mm}$. Most strains present no inhibitory activity against $C$. albicans except strains B6, B1 B4, B10, $\mathrm{C} 3$ and $\mathrm{C} 5$. However the majority of lactobacilli have antagonistic activity against other pathogens.

The results showed that Klebsiella.sp from urinary origin was inhibited by all cultures and their supernatants except supernatants of B1, C3, C5, and the culture of strain $\mathrm{C} 3$. Inhibition zones were shown to be produced by lactobacilli, as they disappeared when we used the supernatant of the most isolates with the exception for supernatant obtained from a number of strains such as B6 and B10 which have the ability of inhibiting vaginal and urinary pathogens.

\subsection{Antibiotic Resistance}

The results showed that all strains were resistant to Ofloxacin, Gentamicin, and Ciprofloxacin; with almost all strains were sensitive to TrimethoprimSulphamethoxazole, Ampicillin, Erythromycin, Cefotaxime, Chloramphenicol, Tetracycline and Nitrofurantoin (Table 4).

\subsection{Resistance of Vaginal Lactobacilli to Spermicides and Acid Production}

The results of the test are summarized in Table 5. We found that all strains show not an inhibition zone with the first two concentrations $(0.1 \%, 0.2 \%)$, while when a concentration increases to $1 \%$, inhibition zones between 
Bouridane H. et al.

Table 4. Antibiotic susceptibility of some vaginal lactobacilli

\begin{tabular}{|c|c|c|c|c|c|c|c|c|c|c|}
\hline \multirow[t]{3}{*}{ Isolates } & \multicolumn{10}{|c|}{ Antibiotics } \\
\hline & SXT & AM & OFX & GEN & CIP & ERY & CTX & $\mathrm{CHL}$ & TET & NIT \\
\hline & \multicolumn{10}{|c|}{ Inhibition zone (mm) } \\
\hline A1 & $25.5 \pm 0.5^{\mathrm{S}}$ & $22.5 \pm 0.5^{S}$ & $00^{R}$ & $09.5 \pm 1.5^{R}$ & $00^{R}$ & $25.5 \pm 0.5^{S}$ & $30.0 \pm 2.0 \mathrm{~s}$ & $33.0 \pm 1.0^{\mathrm{S}}$ & $21.0 \pm 0.0^{\mathrm{S}}$ & $31.5 \pm 1.5^{S}$ \\
\hline A2 & $22.5 \pm 2.5^{\mathrm{S}}$ & $23.0 \pm 1.0^{\mathrm{S}}$ & $00 \mathrm{R}$ & $10.5 \pm 0.5 \mathrm{R}$ & $00 \mathrm{R}$ & $25.0 \pm 1.0^{\mathrm{S}}$ & $27.5 \pm 2.5^{s}$ & $33.0 \pm 0.0 \mathrm{~s}$ & $17.5 \pm 1.5^{\prime}$ & $32.5 \pm 1.5 \mathrm{~S}$ \\
\hline A3 & $26.0 \pm 1.0 \mathrm{~s}$ & $23.0 \pm 2.0 \mathrm{~s}$ & $00^{R}$ & $09.0 \pm 1.0^{R}$ & $00^{R}$ & $23.5 \pm 0.5 \mathrm{~s}$ & $27.0 \pm 0.0^{s}$ & $31.0 \pm 1.0 \mathrm{~s}$ & $21.0 \pm 1.0 \mathrm{~s}$ & $30.0 \pm 1.0 \mathrm{~s}$ \\
\hline A4 & $23.5 \pm 0.5 \mathrm{~S}$ & $23.0 \pm 4.0 \mathrm{~s}$ & $00^{R}$ & $10.5 \pm 1.0^{R}$ & $00^{R}$ & $24.5 \pm 1.5^{S}$ & $27.5 \pm 2.5 \mathrm{~s}$ & $33.5 \pm 0.5 \mathrm{~s}$ & $22.0 \pm 0.0^{\mathrm{S}}$ & $32.5 \pm 0.5 \mathrm{~s}$ \\
\hline A5 & $24.5 \pm 2.5^{S}$ & $25.0 \pm 1.0 \mathrm{~s}$ & $00^{R}$ & $10.0 \pm 0.0^{R}$ & $00^{R}$ & $23.5 \pm 1.5^{S}$ & $25.0 \pm 2.0 \mathrm{~s}$ & $29.0 \pm 1.0 \mathrm{~S}$ & $20.5 \pm 0.5^{\prime}$ & $29.5 \pm 0.5 \mathrm{~S}$ \\
\hline B1 & $25.0 \pm 1.0^{\mathrm{S}}$ & $21.5 \pm 1.5 \mathrm{~S}$ & $00 \mathrm{R}$ & $10.0 \pm 0.0^{R}$ & $00 \mathrm{R}$ & $22.5 \pm 2.5^{S}$ & $23.0 \pm 2.0 \mathrm{~s}$ & $29.0 \pm 0.0 \mathrm{~S}$ & $20.5 \pm 0.5$ & $31.0 \pm 0.0 \mathrm{~s}$ \\
\hline B3 & $24.5 \pm 1.5^{S}$ & $24.5 \pm 1.5^{\mathrm{S}}$ & $00^{R}$ & $09.5 \pm 0.5 R$ & $00^{R}$ & $21.5 \pm 1.5^{S}$ & $25.0 \pm 2.0$ & $27.5 \pm 2.5^{S}$ & $20.0 \pm 0.0^{\prime}$ & $29.0 \pm 1.0^{\mathrm{S}}$ \\
\hline B4 & $25.5 \pm 0.5 \mathrm{~S}$ & $21.5 \pm 1.5 \mathrm{~S}$ & $00^{R}$ & $11.5 \pm 0.5^{R}$ & $00^{R}$ & $21.0 \pm 1.0 \mathrm{~s}$ & $20.0 \pm 3.0^{\prime}$ & $29.5 \pm 0.5 \mathrm{~S}$ & ו' 18.0 ا 18.0 & $29.0 \pm 0.0 \mathrm{~s}$ \\
\hline B6 & $26.0 \pm 1.0 \mathrm{~s}$ & $24.5 \pm 0.5 \mathrm{~s}$ & $00^{R}$ & $10.5 \pm 0.5^{R}$ & $00^{R}$ & $25.0 \pm 0.0 \mathrm{~s}$ & $26.5 \pm 0.5 \mathrm{~s}$ & $31.0 \pm 1.0 \mathrm{~s}$ & $20.5 \pm 0.5^{\prime}$ & $31.0 \pm 0.0 \mathrm{~s}$ \\
\hline B9 & $23.5 \pm 0.5^{s}$ & $21.5 \pm 1.5 \mathrm{~S}$ & $00^{R}$ & $12.0 \pm 0.0^{R}$ & $00^{R}$ & $25.0 \pm 0.0^{\mathrm{s}}$ & $25.5 \pm 0.5 \mathrm{~s}$ & $30.5 \pm 0.5 \mathrm{~s}$ & $20.5 \pm 0.5^{\prime}$ & $30.0 \pm 0.0 \mathrm{~s}$ \\
\hline B10 & $25.5 \pm 1.5^{S}$ & $24.5 \pm 0.5 \mathrm{~s}$ & $00 \mathrm{R}$ & $11.5 \pm 0.5^{R}$ & $00^{R}$ & $24.5 \pm 0.5 \mathrm{~s}$ & $29.0 \pm 1.0 \mathrm{~s}$ & $32.5 \pm 1.5 \mathrm{~S}$ & $23.5 \pm 0.5^{\mathrm{s}}$ & $32.5 \pm 0.5 \mathrm{~s}$ \\
\hline C3 & $23.0 \pm 2.0^{\mathrm{S}}$ & $15.0 \pm 0.5^{R}$ & $00 \mathrm{R}$ & $10.5 \pm 0.5 R$ & $00^{R}$ & $25.0 \pm 0.0 \mathrm{~s}$ & $28.5 \pm 1.5 \mathrm{~s}$ & $30.5 \pm 0.5 \mathrm{~s}$ & $21.0 \pm 0.0^{\mathrm{s}}$ & $32.5 \pm 2.5 \mathrm{~s}$ \\
\hline C5 & $25.0 \pm 1.0^{\mathrm{S}}$ & $20.0 \pm 1.0$ I & $00^{R}$ & $10.5 \pm 0.5 \mathrm{R}$ & $00 \mathrm{R}$ & $23.5 \pm 1.5 \mathrm{~S}$ & $28.5 \pm 3.5 \mathrm{~s}$ & $32.5 \pm 2.5 \mathrm{~S}$ & $20.0 \pm 0.0^{\prime}$ & $31.0 \pm 1.0 \mathrm{~s}$ \\
\hline W5 & $24.5 \pm 0.5^{S}$ & $25.0 \pm 0.0^{\mathrm{S}}$ & $00^{R}$ & $10.5 \pm 0.5^{R}$ & $00^{R}$ & $21.0 \pm 1.0 \mathrm{~s}$ & $27.0 \pm 2.0 \mathrm{~s}$ & $33.0 \pm 1.0 \mathrm{~S}$ & $21.0 \pm 1.0^{\mathrm{S}}$ & $32.0 \pm 1.0 \mathrm{~s}$ \\
\hline
\end{tabular}

(STX) Trimethoprim-sulphamethoxazole, (AM) Ampicilin, (OFX) Ofloxacin, (GEN) Gentamicin, (CIP) Ciprofloxacin, (ERY) Erythromycin, (CTX) Cefotaxime, (CHL) Chloramphenicol, (TET) Tetracycline, (NIT) Nitrofurantoin

3.5 and $7.5 \mathrm{~mm}$ could be measured for 12 strains, except B10 and B6 isolates. A significant inhibition was noted with $2.5 \%$ where zones are in majority $>6.5 \mathrm{~mm}$. Through these results, we conclude that most of the strains are resistant to the tested spermicide and are able to be co-administered with this spermicide for the treatment of vaginal infections.

The results showed that all lactobacilli have an acidifying capacity with a significant difference between strains $(\mathrm{p}<0.05)$. Measuring the initial $\mathrm{pH}$, and the pHs after $4 \mathrm{~h}, 6 \mathrm{~h}$, and $24 \mathrm{~h}$ of incubation shows a decrease in the $\mathrm{pH}$ of the each sample and development of an acid environment with a $\mathrm{pH} \sim 4.0$ that contributes to the maintenance of the high redox potential which can protect the vagina against the invasion of the undesirable microorganisms (Table 5).

\subsection{Identification of the Selected Isolates}

Two strains were retained as they display a high potential of probiotic profile, they were identified by

Table 5. Resistance of vaginal strains to spermicides and acid production

\begin{tabular}{|c|c|c|c|c|c|c|c|}
\hline \multirow[t]{2}{*}{ Isolates } & \multicolumn{4}{|c|}{ Concentration of spermicides (\%) } & \multicolumn{3}{|c|}{$\begin{array}{c}\text { Acid production } \\
\text { Control broth (pH 5.85) }\end{array}$} \\
\hline & 0.1 & 0.25 & 1 & 2.5 & $4 \mathrm{~h}$ & $6 \mathrm{~h}$ & $24 \mathrm{~h}$ \\
\hline $\mathrm{A} 1$ & 00 & 00 & $7.0 \pm 0.0$ & $7.5 \pm 0.5$ & $5.45 \pm 0.010$ & $5.19 \pm 0.050$ & $4.07 \pm 0.010$ \\
\hline $\mathrm{A} 2$ & 00 & 00 & $3.5 \pm 3.5$ & $7.0 \pm 1.0$ & $5.55 \pm 0.005$ & $5.25 \pm 0.010$ & $4.09 \pm 0.010$ \\
\hline A3 & 00 & 00 & $7.0 \pm 0.0$ & $8.0 \pm 0.0$ & $5.56 \pm 0.010$ & $5.23 \pm 0.020$ & $4.08 \pm 0.010$ \\
\hline A4 & 00 & 00 & $8.0 \pm 0.0$ & $11.5 \pm 1.5$ & $5.59 \pm 0.005$ & $4.95 \pm 0.010$ & $4.04 \pm 0.010$ \\
\hline A5 & 00 & 00 & $6.5 \pm 0.5$ & $9.5 \pm 1.5$ & $5.57 \pm 0.010$ & $4.93 \pm 0.020$ & $4.03 \pm 0.010$ \\
\hline B1 & 00 & 00 & $3.5 \pm 3.5$ & $9.0 \pm 2.0$ & $5.67 \pm 0.020$ & $4.97 \pm 0.010$ & $4.04 \pm 0.005$ \\
\hline B3 & 00 & 00 & $6.5 \pm 0.5$ & $7.0 \pm 1.0$ & $5.64 \pm 0.010$ & $4.90 \pm 0.010$ & $4.05 \pm 0.020$ \\
\hline B4 & 00 & 00 & $7.5 \pm 0.5$ & $7.5 \pm 0.5$ & $5.63 \pm 0.005$ & $4.90 \pm 0.030$ & $4.03 \pm 0.005$ \\
\hline B6 & 00 & 00 & $00 \pm 0.0$ & $7.5 \pm 0.5$ & $5.64 \pm 0.010$ & $4.99 \pm 0.010$ & $4.05 \pm 0.005$ \\
\hline B9 & 00 & 00 & $5.5 \pm 0.5$ & $7.5 \pm 0.5$ & $5.59 \pm 0.005$ & $4.94 \pm 0.020$ & $4.02 \pm 0.005$ \\
\hline B10 & 00 & 00 & $00 \pm 0.0$ & $7.0 \pm 0.0$ & $5.41 \pm 0.005$ & $5.14 \pm 0.005$ & $4.17 \pm 0.030$ \\
\hline C3 & 00 & 00 & $6.5 \pm 1.5$ & $6.5 \pm 1.5$ & $5.49 \pm 0.020$ & $5.25 \pm 0.005$ & $4.10 \pm 0.005$ \\
\hline C5 & 00 & 00 & $7.5 \pm 0.5$ & $7.5 \pm 0.5$ & $5.57 \pm 0.010$ & $5.30 \pm 0.010$ & $4.13 \pm 0.005$ \\
\hline W5 & 00 & 00 & $6.5 \pm 0.5$ & $9.5 \pm 1.5$ & $5.57 \pm 0.020$ & $5.32 \pm 0.030$ & $4.11 \pm 0.005$ \\
\hline
\end{tabular}




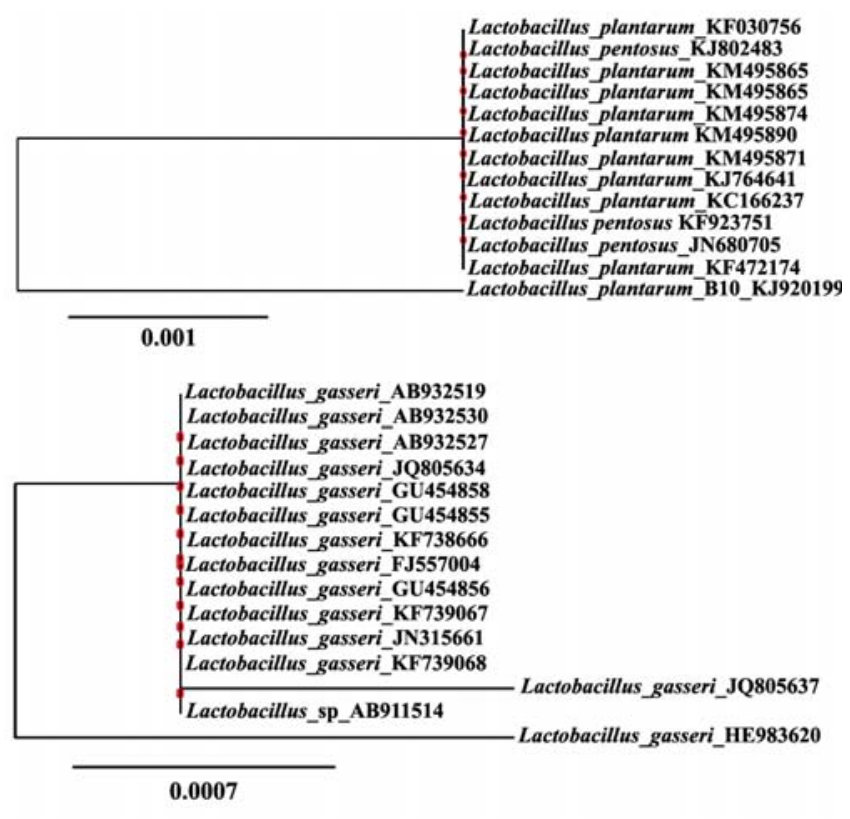

Figure 3. Clustering of Lb. plantarum $\mathrm{B} 10$ and Lb. gasseri $\mathrm{B} 6$

16S rDNA gene sequences and showed a high similarity to $L b$. gasseri (B6: 99\%) and to Lb. plantarum (B10: 99\%). The GenBank accession numbers of the isolates B6 and B10 are assigned as KF739067 and KJ920199, respectively (Figure 3).

\section{Discussion}

In our study, 14 isolates producing $\mathrm{H}_{2} \mathrm{O}_{2}$ were chosen to evaluate their technological and probiotic properties. The production of $\mathrm{H}_{2} \mathrm{O}_{2}$ by lactobacilli is considered as a non specific antimicrobial defense mechanism of the normal vaginal ecosystem (20) since women colonized by $\mathrm{H}_{2} \mathrm{O}_{2}$ producing strains had a protective effect against bacterial vaginosis (28-30). Aroutcheva et al (17) reported that $81.80 \%$ of the isolated strains produce $\mathrm{H}_{2} \mathrm{O}_{2}$ where $38.90 \%$ had a high $\mathrm{H}_{2} \mathrm{O}_{2}$ production. Several studies have demonstrated that Lactobacillus species can be administered orally or vaginally resulting in colonization in vagina, reduction in vaginal coliform counts and even reduction in UGTI (31). Therefore, we studied their viability under acidic, bile and SIF conditions since these abilities are important if the strains are recommended to be used orally as therapeutic probiotic. To exert their beneficial effect, lactobacilli need to resist human gastric transit conditions $(22,32)$. Our results showed that strains B6 and $\mathrm{B} 10$ have the highest tolerance to the gastro-intestinal condition. The results of a similar study have also shown the tolerance of vaginal $L b$. fermentum SK5 to stimulated human gastrointestinal tract conditions (22).

The ability to adhere to the epithelial cells and coaggregation ability are considered as important criterions for in vitro probiotic selection $(15,33,34)$. Our results are in agreement with those of several authors $(10,14)$. Similarly, Strus et al (10) showed that from 111 isolates, $50 \%$ have a high adherence to vaginal mucus.

The relationship between autoaggregation, adhesion and hydrophobicity has been reported by several authors $(7,22,25,35)$, however these correlations have not been found or reported by the others $(36,37)$. The obtained results were in agreement with those reported by Blakrishma (36); as he showed that there is no correlation between these parameters. In another study, Lp9 isolate has surface hydrophobicity of 37$38 \%$, suggesting its adhesiveness (37). Furthermore, adhesion and coaggregation of lactobacilli probiotic may inhibit the adherence of pathogens to the tissue receptors on the vaginal epithelial cells $(12,38)$.

Our isolates present antagonistic activity against indicator bacteria. $\mathrm{H}_{2} \mathrm{O}_{2}$, lactic acid and other organic acids produced by LAB are frequently associated with this activity in vitro (15). The inhibition of urogenital infections increases the relevance of these wild strains for use in probiotic products (39). In another study different inhibitory ability between vaginal lactobacilli strains against $C$. albicans were obtained (40).

It is very important to know the susceptibility of vaginal $L A B$ to antibiotics in order to understand their behavior with respect to antibiotics in pharmaceutical preparations which were used for restoration of unbalanced vaginal flora (16). Probiotic strains' resistance antibiotic may be an advantage in the case of coadministrations, but not all lactobacilli have intrinsic resistance (22).

According to our results, the majority of strains are resistant to the tested spermicide. Pascual et al. (20) have studied the resistance and susceptibility of 62 strains of LAB to spermicide and have shown that $19.4 \%$ were resistant, whereas $80.6 \%$ were sensitive to nonoxynol-9.

The result showed that $L b$. gasseri $\mathrm{B} 6$ produces a high quantity of the lactic acid. It was reported that production of organic acid by LAB in the vaginal environment is responsible for the change in the $\mathrm{pH}$ and when the vaginal $\mathrm{pH}$ was lower than 4.5 it reflects a healthy vaginal ecosystem $(9,17,41)$. According to Aslim and Kilic (19) lactobacilli produce lactic acid to maintain vaginal $\mathrm{pH} \leq 4.5$; this mechanism is used against pathogenic microorganisms. 


\section{Conclusions}

In conclusion, $L b$. gasseri $\mathrm{B} 6$ and $L b$. plantarum $\mathrm{B} 10$ possessed desirable technological and probiotic properties. These Lactobacillus isolates are the best candidate for preventing vaginal and urogenital infections.

\section{Acknowledgments}

This work was supported by a grant allocated by the "Ministère de l'Enseignement Supérieur et de la Recherche Scientifique" of Algeria (Project code: F01720120001).

\section{References}

1. Atassi F, Brassar D, Grob Ph, Servin AL. Lactobacillus strains isolated from the vaginal microbiota of healthy women inhibit Prevotellabivia and Gardnerella vaginalis in coculture and cell culture. FEMS Immunol Med Microbiol. 2006a;48:424432. DOI: 10.1111/j.1574-695X.2006.00162.x

2. Atassi F, Brassar D, Grob Ph, Graf F, Servin AL. Vaginal Lactobacillus isolates inhibit uropathogenic Escherichia coli. FEMS Microbiol Lett. 2006b;257:132-138. DOI: 10.1111/j.1574-6968.2006.00163.x

3. Zárate G, Nader-Macias M. Influence of probiotic vaginal lactobacilli on in vitro adhesion of urogenital pathogens to vaginal epithelial cells. Lett Appl Microbiol. 2006;143:174-180. DOI: $10.1111 / \mathrm{j} .1472-765 \mathrm{x} .2006 .01934 . \mathrm{x}$

4. Gardiner G, Heinemann C, Bruce A, Beuerman D, Reid G. Persistence of Lactobacillus fermentum RC-14 and L. rhamnosus GR-1 but not L. rhamnosus GG in the human vagina as demonstrated by randomly amplified polymorphic DNA. Clin Diagn Lab Immunol. 2002;9:92-96. DOI: 10.1128/CDLI.9.1. 92-96.2002

5. Voravuthikunchai SP, Bilasoi S, Supamala O. Antagonistic activity against pathogenic bacteria by human vaginal lactobacilli. Anaerobe 2006;12:221-226. DOI: 10.1016/j.anaerobe.2006.06.003

6. Garg k B, Ganguli I, Das R, Talwar GP. Spectrum of Lactobacillus species present in healthy vagina of Indian Women. Indian J Med Res. 2009;129:652-657.

7. Kaewsrichan J, Peeyananjarassri K, Kongprasertkit J. Selection and identification of anaerobic lactobacilli producing inhibitory compounds against vaginal pathogens. FEMS Immunol Med Microbiol. 2006;48:75-83. DOI: 10.1111/j.1574695X.2006.00 124.x

8. Gil NF, Martinez RCR, GomesCB, NomizoA, De Martinis ECP. Vaginal lactobacilli as potential probiotic against Candida ssp. Braz J Microbiol. 2010;41:6-14. DOI: org/10.1590/S1517-83822010000100002

9. Dimitonova SP, Danova ST, Serkedjieva JP, Bakalov BV. Antimicrobial activity and protective properties of vaginal lactobacilli from healthy Bulgarian women. Anaerobe 2007;13:178-184. DOI: 10.1016/j.anaerobe.2007.08.003

10. Strus M, Kucharska A, Kukla G, Brzychczy MW, Maresz K, Heczkoi PB. The in vitro activity of vaginal Lactobacillus with probiotic properties against Candida. Infect Dis Obstet Gynecol. 2005;13:69-75. DOI: 10.1080/10647440400028136
11. EO'Hanlon D, Moench TR, Cone RA. In vaginal fluid, bacteria associated with bacterial vaginosis can be suppressed with lactic acid but not hydrogen peroxide. BMC Infect Dis. 2011;11:200-208. DOI: 10.1186/1471-2334-11-200

12. BorisS, Suarez JE, Vazquez F, Barbés C. Adherence of Human Vaginal Lactobacilli to Vaginal Epithelial Cells and Interaction with Uropathogens. Infect Immunol. 1998;66:1985-1989.

13. Ocaña VS, Bru E, Ruiz A, Holgado AP, Nader-Macias ME. Surface characteristics of lactobacilli isolated from human vagina. J Gen Appl Microbiol. 1999;45:203-212.

14. Osset J, Bartolome RM, Garcia E, Andreu A. Assessment of the capacity of Lactobacillus to inhibit the growth of uropathogens and block their adhesion to vaginal epithelial cells. J Infect Dis. 2001;183:485-491. DOI: 10.1086/318070

15. Fraga M, Perelmuter K, Delucchi L, Cidade E, Zunino P. Vaginal lactic acid bacteria in the mare: evaluation of the probiotic potential of native Lactobacillus spp. and Enterococcus spp. Strains. Antonie Van Leeuwenhoek. 2008;93:71-78. DOI: 10.1007/s 10482-007-9180-4

16. Ayenalem S, Yusuf L, Ashenafi M. Lactic Acid Bacterial Vaginosis among Outpatients in Addis Ababa. Ethiop $J$ Health Dev. 2010;24(3):198-204.

17. Aroutcheva A, Gariti D, Simon M, Shott S, Faro J, Simoes JA, et al. Defense factors of vaginal lactobacilli. Am J Obstet Gynecol. 2001;85(2):375-379. DOI: 10.1067/mob.2001.115867

18. Reid G. In vitro testing of Lactobacillus acidophilus NCFM as a possible probiotic for the urogenital tract. Int Dairy J. 2000;10:415-419. DOI: 10.1016/S0958-6946(00)00059-5

19. Aslim B, Kilic E. Some probiotic properties of vaginal lactobacilli isolated from healthy women. Jpn $J$ Infect Dis. 2006;59:249-253.

20. Ascual LM, Daniele MB, Pajaro C, Barberis L. Lactobacillus species isolated from the vagina: identification, hydrogen peroxide production and nonoxynol-9 resistance. Contraception 2006;73:78-81. DOI: 10.1016/j.contraception.2005.06.066

21. Yixu H, Tian W, Wan C, Jia L, Wang L, Yuan J, et al. Antagonistic Potential against Pathogenic Microorganisms and Hydrogen Peroxide Production of Indigenous Lactobacilli Isolated from Vagina of Chinese Pregnant Women. Biomed Environ Sci. 2008;21:365-371. DOI: 10.1016/S0895-3988(08)60056-2.

22. Kaewnopparat S, Dangmanee N, Kaewnopparat N, Srichana T, Chulasiri M, Settharaksa S. In vitro probiotic properties of Lactobacillus fermentum SK5 isolated from vagina of a healthy woman. Anaerobe 2013;22:6-13. DOI: 10.1016/j.anaerobe.2013.04.009

23. Woraharn S, Chaiyasut C, Sirithunyalug B, Sirithunyalug J. Survival enhancement of probiotic Lactobacillus plantarum CMU-FP002 by granulation and encapsulation techniques. Afr J Microbiol Res. 2010;4(20):2086-2093.

24. Mclean NW, Rosenstenin IJ. Characterization and selection of Lactobacillus species to re-colonise the vagina of women with recurrent bacterial vaginosis. J Med Microbiol. 2000;49:543552. DOI: 10.1099/0022-1317-49-6-543.

25. Kos B, Šuškovic J, Vukoviæ S, Šimpraga M, Frece J, Matošiæ S. Adhesion and aggregation ability of probiotic strain Lactobacillus acidophilus M92. J Appl Microbiol. 2003;94:981-987. DOI: 10.1046/j.1365-2672.2003.01915.x

26. Iyer R, Tomar SK, Kapila S, Mani J, Singh R. Probiotic proper- 
ties of folate producing Streptococcus thermophilus strains. Food Res Int. 2010;43:103-110. DOI : 10.1016/j.foodres.2009.09.011

27. Vlkova'E, RadaV, Popela'riova'P, Trojanova'I, Killer J. Antimicrobial susceptibility of bifidobacteria isolated from gastrointestinal tract of calves. Livest Sci. 2006;105:253-259. DOI: 10.1016/j.livsci.2006.04.011

28. Dasari S, Shouri RND, Wudayagiri R, Valluru L. Antimicrobial activity of Lactobacillus against microbial flora of cervico vaginal infections. Asian Pac J Trop Dis. 2014;4(1):18-24. DOI: 10.1016/S2222-1808(14)60307-8

29. Vallor AC, Antonio MAD, Hawes SE, Hillier SL. Factors associated with acquisition of, or persistent colonization by, vaginal lactobacilli: role of hydrogen peroxide production. $J$ Infect Dis. 2001;184:1431-1436. DOI: 10.1086/324445

30. Merk K, Borelli C, Korting HC. Lactobacilli-bacteria-host interactions with special regard to the urogenital tract. Int $J$ Med Microbiol. 2005;295:9-18. DOI: 10.1016/j.ijmm.2004.11.006

31. Reid G, Burton J, Devillard E. The Rationale for Probiotics in Female Urogenital Healthcare. Med Gen Med. 2004;6(1):49-62.

32. Vinderola CG, Reinheimer JA. Lactic acid starter and probiotic bacteria: a comparative in vitro study of probiotic characteristics and biological barrier resistance. Food Res Int. 2003;36:895-904. DOI: 10.1016/s0963-9969(03)00098-x

33. Nivoliez A, Camares O, Paquet- Gachinat M, Bornes S, Forestier $\mathrm{Ch}$,Veisseire $\mathrm{PH}$. Influence of manufacturing processes on in vitro properties of the probiotic strain Lactobacillus rhamnosus Lcr35. J Biotechnol. 2012;160:236241. DOI: $10.1016 /$ j.jbiotec.2012.04.005

34. Ekmekci H, Aslim B, Ozturk S. Characterization of vaginal lactobacilli coaggregation abbility with Escherichia coli. Microbiol Immunol. 2009;53:59-65. DOI: 10.1111/j.1348- 0421.2009.00115.x

35. Collado MC, Meriluoto J. Adhesion and aggregation properties of probiotic and pathogen strains. Eur Food Res Technol. 2008;226:1065-1073. DOI 10.1007/s00217-007-0632-x

36. Balakrishna A. In vitro evaluation of adhesion and aggregation abilities of four potential probiotic strains isolated from guppy (Poeciliareticulata). Braz Arch Biol Technol. 2013;56(5):793-800. DOI :org/10.1590/S1516-89132013000500010.

37. Kaushik JK, Kumar A, Duary RK, Mohanty AK, Grover S, Batish VK. Functional and Probiotic Attributes of an Indigenous Isolate of Lactobacillus plantarum. PLoSONE. 2009. DOI: 10.1371/journal.pone.0008099.

38. Mastromarino P, Brigidi P, Macchia S, Maggi L, Pirovano F, Trinchieri V, et al. Characterization and selection of vaginal Lactobacillus strains for the preparation of vaginal tablets. $J$ Appl Microbiol. 2002;93:884-893. DOI: 10.1046/j.13652672.2002.01759.x

39. Juàrez Tomàs MS, Ocana SV, Wiese B, Nader-Macias ME. Growth and lactic acid production by vaginal Lactobacillus acidophilus CRL 1259 and inhibition of uropathogenic Escherichia coli. J Med Microbiol. 2003;52:1117-1124. DOI: 10.1016/j.ejogrb.2011.07.010

40. Rousseau V, Lepargneurb JP, Roquesc C, Remaud-Simeond M, Paul F. Prebiotic effects of oligosaccharides on selected vaginal lactobacilli and pathogenic microorganisms. Anaerobe.2005;11:145-153. DOI: $10.1016 /$ j.anaerobe.2004.12.002

41. Matu MN, Orinda GO, Njagi ENM, Cohen CR, Bukusi EA. In vitro inhibitory activity of human vaginal lactobacilli against pathogenic bacteria associated with bacterial vaginosis in Kenyan women. Anaerobe. 2010;16:210-215. DOI: 10.1016/j.anaerobe.2009.11.002 